Article

\title{
Intrinsic photocatalytic water oxidation activity of Mn-doped ferroelectric $\mathrm{BiFeO}_{3}$
}

\author{
Jafar Hussain Shah a,b Anum Shahid Malik a,b, Ahmed Mahmoud Idris a,b, Saadia Rasheed a,b, \\ Hongxian Han a,*, Can Li a \\ a State Key Laboratory of Catalysis \& Division of Solar Energy, Dalian National Laboratory for Clean Energy, Dalian Institute of Chemical Physics, \\ Chinese Academy of Sciences, Dalian 116023, Liaoning, China \\ ${ }^{\mathrm{b}}$ University of Chinese Academy of Sciences, Beijing 100049, China
}

\section{A R T I C L E I N F}

\section{Article history:}

Received 21 July 2020

Accepted 21 September 2020

Available online 22 November 2020

\section{Keywords:}

Photocatalytic water oxidation

Bandgap engineering

Bismuth ferrite

Ferroelectric materials

Cation doping

\begin{abstract}
A B S T R A C T
The development of stable and efficient visible light-absorbing oxide-based semiconductor photocatalysts is a desirable task for solar water splitting applications. Recently, we proposed that the low photocurrent density in film-based $\mathrm{BiFeO}_{3}(\mathrm{BFO})$ is due to charge recombination at the interface of the domain walls, which could be largely reduced in particulate photocatalyst systems. To demonstrate this hypothesis, in this work we synthesized particulate $\mathrm{BFO}$ and $\mathrm{Mn}$-doped $\mathrm{BiFeO}_{3}$ (Mn-BFO) by the sol-gel method. Photocatalytic water oxidation tests showed that pure BFO had an intrinsic photocatalytic oxygen evolution reaction (OER) activity of $70 \mu \mathrm{mol} \mathrm{h} \mathrm{h}^{-1} \mathrm{~g}^{-1}$, while BFO-2, with an optimum amount of Mn doping (0.05\%), showed an OER activity of $255 \mu \mathrm{mol} \mathrm{h} \mathrm{h}^{-1} \mathrm{~g}^{-1}$ under visible light $(\lambda \geq 420 \mathrm{~nm}$ ) irradiation. The bandgap of Mn-doped BFO could be reduced from 2.1 to $1.36 \mathrm{eV}$ by varying the amount of Mn doping. Density functional theory (DFT) calculations suggested that surface Fe (rather than $\mathrm{Mn}$ ) species serve as the active sites for water oxidation, because the overpotential for water oxidation on Fe species after Mn doping is $0.51 \mathrm{~V}$, which is the lowest value measured for the different Fe and Mn species examined in this study. The improved photocatalytic water oxidation activity of Mn-BFO is ascribed to the synergistic effect of the bandgap narrowing, which increases the absorption of visible light, reduces the activation energy of water oxidation, and inhibits the recombination of photogenerated charges. This work demonstrates that Mn doping is an effective strategy to enhance the intrinsic photocatalytic water oxidation activity of particulate ferroelectric BFO photocatalysts.
\end{abstract}

(C) 2021, Dalian Institute of Chemical Physics, Chinese Academy of Sciences. Published by Elsevier B.V. All rights reserved.

\section{Introduction}

Photocatalytic water splitting is considered one of the most viable approaches to convert sunlight into chemical forms of hydrogen energy, which is a clean and renewable resource [1]. Three basic steps are involved in solar-driven water splitting using a potential semiconductor photocatalyst: (1) light absorption and generation of charges (electrons and holes), (2) separation of photogenerated charges into electrons and holes, and (3) transfer of the photogenerated charges to the surface, to participate in the water splitting reactions. Among these three steps, charge separation and transfer (CST) is regarded as

\footnotetext{
* Corresponding author. Tel: +86-411-84379760; Fax: +86-0411-84694447; E-mail: hxhan@dicp.ac.cn This work was supported by the National Key R\&D Program of China (2017YFA0204804) and the National Natural Science Foundation of China (21761142018, 21473189).
} 
the key energy-pumping step, and the water oxidation reaction at the surface is considered the most challenging process for neutral water splitting, because it is an energetically uphill and non-spontaneous four-electron transfer [2,3]. The development of extended visible light-absorbing semiconductor photocatalysts with efficient CST for water oxidation is a necessary requirement for achieving effective photocatalytic water splitting $[2,4,5]$.

Bandgap engineering strategies, such as elemental doping, have been widely applied to enhance the light absorption capability and tune the electronic structure of semiconductor photocatalysts in order to achieve a more efficient CST. For example, nitrogen and sulfur anion doping of metal oxide semiconductors, to form oxynitrides and oxysulfides such as $\mathrm{Ta}_{3} \mathrm{~N}_{5}$, $\mathrm{TaON}, \mathrm{Ga}_{1-x} \mathrm{Zn}_{x} \mathrm{~N}_{1-x} \mathrm{O}_{x}$, and $\mathrm{Ln}_{2} \mathrm{Ti}_{2} \mathrm{~S}_{2} \mathrm{O}_{5}$, has been shown to be an efficient strategy to extend the light absorption (from the UV to the visible region) with suitable electronic band structures for water splitting [6-10]. Nevertheless, these anion-doped semiconductor photocatalysts are usually unstable and cannot sustain long-term photocatalytic reactions owing to photocorrosion. In this regard, we propose to explore another approach, that is, cation doping of oxide semiconductors to enhance their light absorption and tune their electronic structure for water splitting $[11,12]$. Our preliminary studies already showed that double perovskite oxide semiconductors could serve as efficient bifunctional photocatalysts for both oxygen and hydrogen evolution [13-15].

Bi-based oxide semiconductor materials such as $\mathrm{BiVO}_{4}$, $\mathrm{Bi}_{2} \mathrm{WO}_{6}, \mathrm{BiOX}(X=\mathrm{Cl}$ or $\mathrm{Br})$, and $\mathrm{Bi}_{4} \mathrm{NbO}_{8} \mathrm{Cl}$ have been extensively studied as visible light-absorbing semiconductor photocatalysts for water splitting [16-19]. These semiconductors are advantageous for tuning the bandgap and electronic structure, because $\mathrm{Bi} 6 \mathrm{~s}$ can contribute to the density of states (DOS) of both the valence and conduction bands (VB and $\mathrm{CB}$, respectively) $[20,21]$. This results in bandgap narrowing, leading to a higher absorption of visible light, and even to a decrease of the effective masses of the charge carriers for an efficient CST $[22,23]$. Among Bi-based oxide semiconductors, we are particularly interested in $\mathrm{BiFeO}_{3}$ (BFO), which is a ferroelectric oxide semiconductor with a narrow bandgap of $2.0-2.2 \mathrm{eV}$, similar to that of $\mathrm{Fe}_{2} \mathrm{O}_{3}$. BFO has been extensively studied for photoelectrochemical water splitting, but its overall efficiency is very low $[24,25]$. Our recent work showed that the factor limiting the photocurrent density in BFO thin films is the severe recombination of photogenerated charges at the interface of the domain walls [26]. This result provides another opportunity to exploit the unique spontaneous polarization field of ferroelectric materials for achieving an efficient CST in particulate form; this is because nanoparticles possess a much smaller number of domains than film materials, so that the close contact between the particles can be avoided, largely inhibiting the recombination of photogenerated charges at the interface of the domain walls.

A literature survey shows that a variety of strategies have been explored to improve the photocatalytic activity of BFO [27-30]. For example, it was reported that doping with La, Gd, $\mathrm{Y}$, and Ti to replace either Bi or Fe sites can enhance the photocatalytic activity of BFO [31-33]. Co-doping of Mn with other elements has been reported to improve the environmental photocatalysis $[34,35]$ or photoelectrocatalytic reactions of BFO [36]. In this work, Mn-doped BFO was synthesized and tested in the photocatalytic oxygen evolution reaction (OER). Mn was chosen as BFO dopant because of the following considerations: (1) Mn doping may lead to distortion of the $\mathrm{FeO}_{6}$ octahedra, which may affect the multiferroic, dielectric, or ferroelectric properties of BFO [37,38]; (2) the ionic radius of $\mathrm{Mn}^{3+}$ is similar to that of $\mathrm{Fe}^{3+}$; hence, $\mathrm{Mn}$ doping may retain the crystalline structure of BFO; (3) as $\mathrm{Mn}$ is a transition metal able to produce interband electronic states within the bandgap of BFO [39], we aim to exploit its electronic configuration with half-filled $d_{5}$ orbitals to efficiently separate and transfer photogenerated charges.

Considering our goal to develop stable oxide-based semiconductor photocatalysts and the intriguing ferroelectric nature of BFO, with a spontaneous polarization field for CST, Mn-doped BFO was selected as the subject of this study. The $\mathrm{Mn}$ doping level was optimized by comparing a series of Mn-doped BFO samples [denoted as $\mathrm{BFe}_{1-x} \mathrm{Mn}_{x} \mathrm{O}_{3}, x=0.025 \%$, $0.05 \%, 0.075 \%$, and $0.1 \%$ (molar ratio)] synthesized using the sol-gel method. The effects of Mn doping on the bandgap and electronic structures of BFO were studied by diffuse reflectance spectroscopy (DRS), Mott-Schottky analysis, and DOS calculated by density functional theory (DFT). A Mn doping ratio of $0.05 \%$ led to the highest photocatalytic OER activity of 255 $\mu \mathrm{mol} \mathrm{h} \mathrm{h}^{-1} \mathrm{~g}^{-1}$ under visible light irradiation. The effect of $\mathrm{Mn}$ doping on the active sites for water oxidation was also studied by DFT calculations. The results suggested that Mn doping leads to a synergetic bandgap-narrowing effect, which increases the absorption of visible light and reduces the overpotential for water oxidation, leading to enhanced activity for photocatalytic water oxidation.

\section{Experimental}

\subsection{Synthesis of BFO and Mn-BFO nanoparticles}

Detailed information about the chemicals used for the synthesis of BFO and Mn-doped BFO samples, as well as on the physical characterization, DFT calculations, and tests of photocatalytic water oxidation activity are provided in the Supplementary Information (SI). BFO nanoparticles were synthesized using the sol-gel method. Typically, $\mathrm{Bi}\left(\mathrm{NO}_{3}\right)_{3} \cdot 5 \mathrm{H}_{2} \mathrm{O}$ and $\mathrm{Fe}\left(\mathrm{NO}_{3}\right)_{3} \cdot 9 \mathrm{H}_{2} \mathrm{O}(\mathrm{Bi} / \mathrm{Fe}$ molar ratio $=1.1: 1)$ were dissolved in $100 \mathrm{~mL}$ of ethylene glycol containing tartaric acid, and stirred for $48 \mathrm{~h}$ at $80^{\circ} \mathrm{C}$ until a yellowish green powder was obtained. The powder was ground using a mortar and pestle into a fine powder, which was calcined at $500{ }^{\circ} \mathrm{C}$ for $60 \mathrm{~min}$. After calcination, the sample was washed several times with distilled water and dried at $80^{\circ} \mathrm{C}$ for $6 \mathrm{~h}$. For the synthesis of Mn-BFO samples, the amount of Mn doping was varied from 0.025 to $0.1 \%$. The general molecular formula of the Mn-BFO samples is $\mathrm{BF}_{1-x} \mathrm{Mn}_{x} \mathrm{O}_{3}$ (with $x=0.025,0.050,0.075$, and 0.1 denoting the molar percentage). For simplicity, the Mn-BFO samples with Mn molar percentages of $0.025 \%, 0.050 \%, 0.075 \%$, and $0.1 \%$ are denoted as BFO-1, BFO-2, BFO-3, and BFO-4, respectively. 

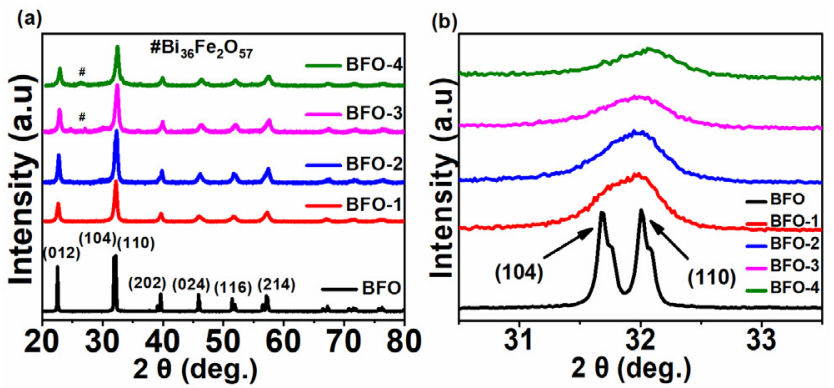

Fig. 1. (a) XRD patterns of the BFO, BFO-1, BFO-2, BFO-3 and BFO-4; (b) Enlarged patterns of (104) and (110) peaks for BFO, BFO-1, BFO-2, BFO-3 and BFO-4.

\section{Results and discussion}

The crystallinities of the BFO- and Mn-doped $\mathrm{BF}_{1-x} \mathrm{Mn}_{x} \mathrm{O}(x=$ $0.025 \%, 0.050 \%, 0.075 \%$, and $0.1 \%$ molar ratio) nanoparticles were analyzed by examining their X-ray diffraction (XRD) patterns (Fig. 1(a)). All samples had high crystallinity. The dominant (012), (104), (110), (202), (024), (116), and (214) diffraction peaks can be well indexed to PDF card no. 86-1518, corresponding to the rhombohedral perovskite crystal structure with space group $R 3 c$. After Mn doping, the (110) and (104) diffraction peaks were shifted to higher angles and merged together, giving rise to a wider peak (Fig. 1(b)). This indicates that Mn doping induces distortion of the BFO lattice structure $[27,40]$. Some small peaks attributed to $\mathrm{Bi}_{36} \mathrm{Fe}_{2} \mathrm{O}_{57}$ were observed for the BFO-3 and BFO-4 samples with higher Mn doping. Generally, it is very difficult to obtain pure-phase BFO nanoparticles by high-temperature synthesis, because of the volatile nature of Bi. Formation of secondary phases is generally observed in the literature [37]. Doping foreign elements in BFO may also generate some impurities, due to changes in crystalline kinetics or difficulty in controlling the stoichiometric reac-
Table 1

Particle sizes and bandgap energies of all samples.

\begin{tabular}{lcc}
\hline Sample & Particle Size $(\mathrm{nm})$ & Bandgap $(\mathrm{eV})$ \\
\hline BFO & 130 & 2.1 \\
BFO-1 & 50 & 1.52 \\
BFO-2 & 40 & 1.46 \\
BFO-3 & 38 & 1.4 \\
BFO-4 & 34 & 1.36 \\
\hline
\end{tabular}

tions as desired [38]. In fact, we observed that the crystallization process became sluggish, as it took longer to form the solid precursor when the amount of Mn precursor was increased.

Fig. 2(a) shows the DRS spectra of the BFO and Mn-doped BFO samples. The spectra show an obvious red shift from the visible region for pure $\mathrm{BFO}$ to the near-infrared region for the sample with the highest Mn content (BFO-4). The increase in Mn content improved the light absorption properties, indicating that Mn doping had a positive effect on the optical properties of BFO. The bandgap energies calculated using the Kubelka-Munk method (Fig. 2(b)) are shown in Table 1 [41]. Pure BFO showed a $550 \mathrm{~nm}$ absorption edge corresponding to a bandgap of $2.1 \mathrm{eV}$, while BFO-2 exhibited an absorption edge at $800 \mathrm{~nm}$, corresponding to a bandgap of $1.46 \mathrm{eV}$. The theoretical bandgap values determined by the DOS curves calculated using the DFT approach match well with the experimental results, as BFO and BFO-2 showed bandgaps of $2.05 \mathrm{eV}$ (Fig. 2(c)) and $1.53 \mathrm{eV}$ (Fig. 2(d)), respectively. The comparison of the partial and total DOS curves of BFO and BFO-2 indicates that the bandgap narrowing of Mn-doped BFO-2 is due to the contribution of the Mn $3 d$ orbital to both the VB and CB [24,42]. The Mott-Schottky plots of BFO and BFO-2 reveal that these materials are p-type semiconductors (Fig. 2(e)). The flat-band potentials of BFO and BFO-2 were found to be 1.7 and $1.6 \mathrm{~V} v$ s. normal hydrogen electrode (NHE), respectively. Hence, the VB (a)

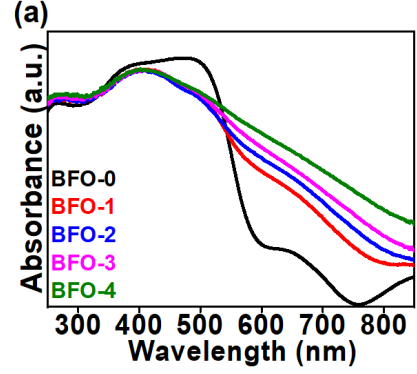

(d)

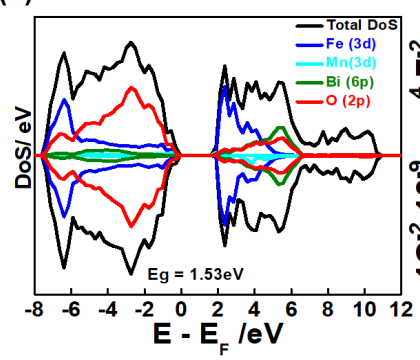

(b)

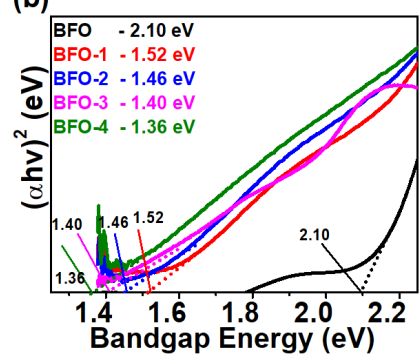

(e)

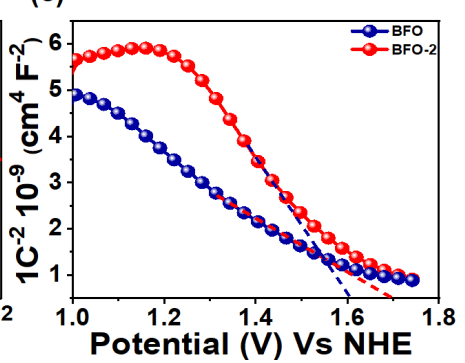

(c)

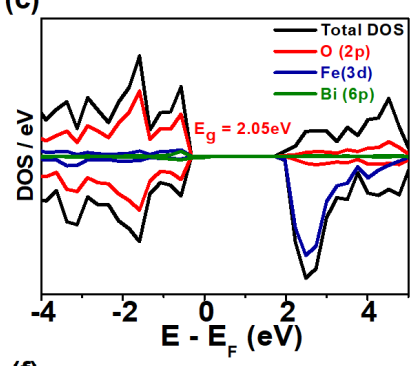

(f)

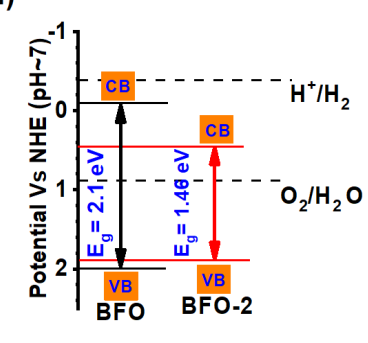

Fig. 2. (a) DRS of the BFO, BFO-1, BFO-2, BFO-3 and BFO-4; (b) Tauc's plot for bandgap calculations of the BFO, BFO-1, BFO-2, BFO-3 and BFO-4. Partial and total DOS calculations using DFT for BFO (c) and BFO-2 (d); (e) Mott-Schottky plots of BFO and BFO-2; (f) Energy band diagram showing the band edges of BFO and BFO-2. 
(a)

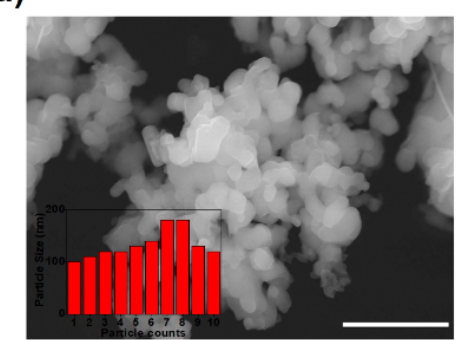

(d)

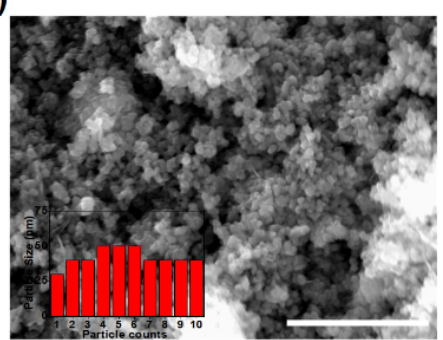

(b)

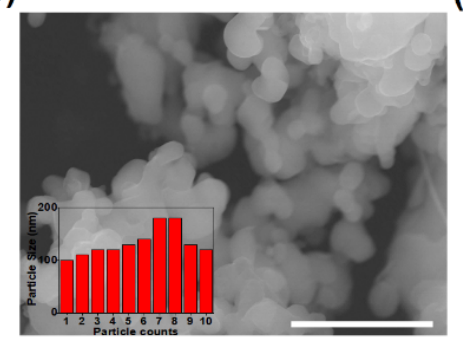

(e)

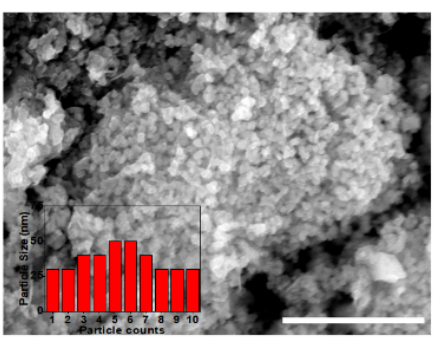

(c)

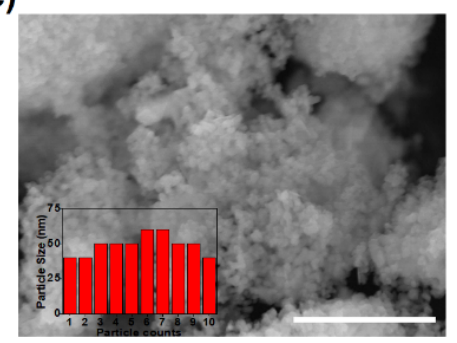

(f)

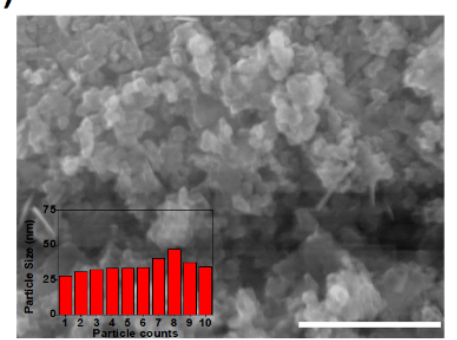

Fig. 3. HR-SEM images of BFO (a,b), BFO-1 (c), BFO-2 (d), BFO-3 (e), and BFO-3 (f). (Scale bar $1 \mu \mathrm{m})$. Insets in (a-f) show the distribution of particle size of all the samples, respectively.

positions of BFO and BFO-2 can be estimated to be 2.0 and 1.9 $\mathrm{V} v$ s. NHE, respectively. As the VB position of p-type semiconductors is generally $0.3 \mathrm{~V}$ more positive than the flat-band potential of the material [26], the CB positions of BFO and BFO-2 can be determined to be $c a$. -0.11 and $0.44 \mathrm{~V}$ vs. NHE, respectively. The energy band structure shown in Fig. 2(f) indicates that both $\mathrm{BFO}$ and BFO-2 nanoparticles are thermodynamically favorable for the photocatalytic OER, but not for the hydrogen evolution reaction (HER); this is because their VB positions are much more positive than the theoretical potential of $1.23 \mathrm{eV}$ for water oxidation, whereas the $\mathrm{CB}$ positions are not negative enough to reduce protons and evolve hydrogen. The Mn-doped BFO may serve as a narrow-bandgap visible light-absorbing semiconductor photocatalyst for water oxidation.

The effect of Mn doping on the morphology was studied by high-resolution scanning electron microscopy (HR-SEM), and the results are shown in Figs. 3(a-f). Interestingly, it was found that increasing the amount of Mn doping significantly decreased the size of the nanoparticles (Figs. 3(a-f), inset). The particle sizes were calculated from the HR-SEM images using the Nanomeasure software, and the results are presented in Table 1. Because the synthesis conditions for the BFO and Mn-doped BFO samples are similar, the decrease in particle size upon Mn doping could be ascribed to the smaller ionic radius of $\mathrm{Mn}^{3+}$ compared to $\mathrm{Fe}^{3+}$, which inhibits the nucleation and growth of the BFO crystals [43]. Fig. 4 shows the energy-dispersive X-ray (EDX) elemental mapping and graphical analysis of the BFO-2 sample, while the corresponding plot and elemental mapping for BFO are shown in Fig. S1. These results indicate that the $\mathrm{Bi}, \mathrm{Fe}, \mathrm{Mn}$, and $\mathrm{O}$ elements are distributed uniformly in the samples, which is a strong indication of the successful synthesis of Mn-doped BFO.

The valence states of $\mathrm{Bi}, \mathrm{Fe}, \mathrm{Mn}$, and $\mathrm{O}$ in Mn-doped BFO (BFO-2) were studied by XPS. The XPS survey scan of BFO-2 and the XPS analysis of BFO are shown in Fig. S2. The Bi $4 f$ XPS profile in Fig. 5(a) shows two clear peaks at binding energies of 158.25 and $163.6 \mathrm{eV}$, which match well with the $\mathrm{Bi} 4 f_{7 / 2}$ and $\mathrm{Bi}$ $4 f_{5} / 2$ states, respectively. The binding energy difference between the $4 f_{7 / 2}$ and $4 f_{5 / 2}$ signals is $5.3 \mathrm{eV}$, which is attributed to the $\mathrm{Bi}^{3+}$ species of $\mathrm{Bi}-\mathrm{O}$ bonds in BFO [44]. Fig. 5(b) shows the XPS profile of $\mathrm{Fe}$, with peaks at binding energies of 723.6, 718, and $710 \mathrm{eV}$ corresponding to Fe $2 p_{1 / 2}, 2 p_{\text {sat, }}$ and $2 p_{3 / 2}$, respectively, which are characteristic of the $\mathrm{Fe}^{3+}$ oxidation state. Moreover, the satellite peak at $718 \mathrm{eV}$ (usually 6-8 eV above the $2 p_{3 / 2}$ signal) indicates the presence of Fe in different electronic configurations, and is also regarded as the result of the overlapping between $\mathrm{Fe}^{2+}$ and $\mathrm{Fe}^{3+}$ oxidation states [44]. Fig. 5(c) shows the spectra of $01 s$ core levels, which could be deconvoluted into three peaks at binding energies of 528.9, 529.74, and $531 \mathrm{eV}$, respectively. The peaks at 528.9 and $529.74 \mathrm{eV}$ correspond to the lattice oxygen species of Bi-O and Fe-O bonds, respectively. The peak at $531 \mathrm{eV}$ could be attributed to oxygen vacancies or surface-adsorbed oxygen [26]. The XPS profile of Mn in Fig. 5(d) shows two main energy peaks
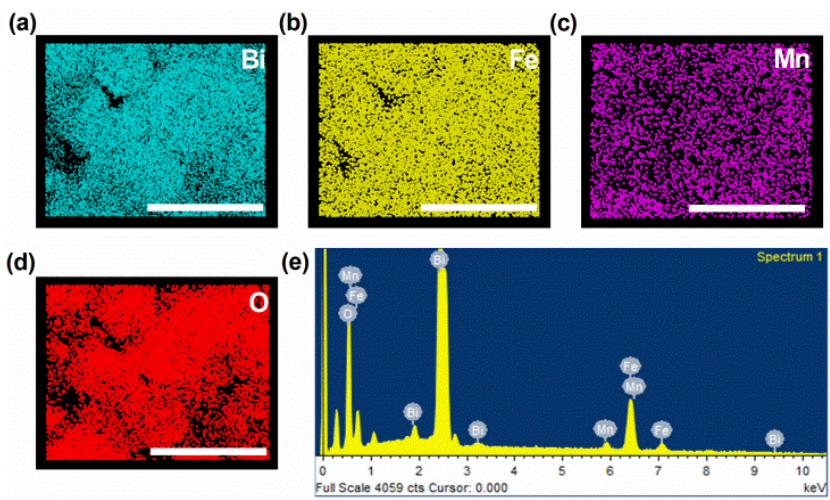

Fig. 4. EDS elemental mapping for BFO-2. (a) Bi; (b) Fe; (c) Mn; (d) O. (scale bar $3 \mu \mathrm{m}$ ). (e) EDS analysis graph indicating the presence of $\mathrm{Bi}$, $\mathrm{Fe}, \mathrm{O}$ and $\mathrm{Mn}$. 
(a)

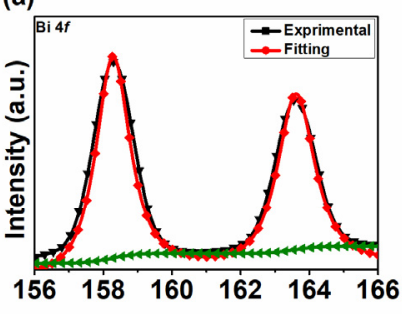

(c)

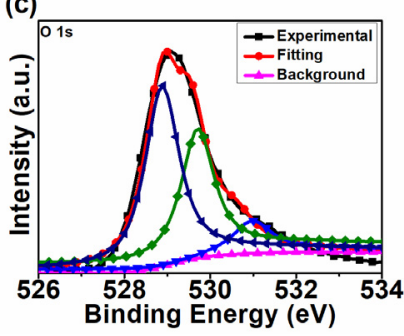

(b)

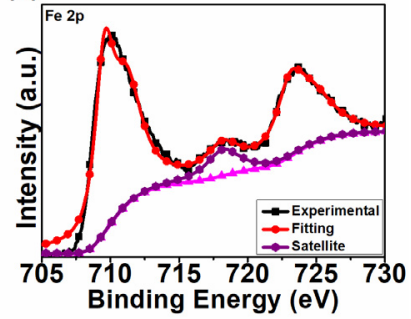

(d)

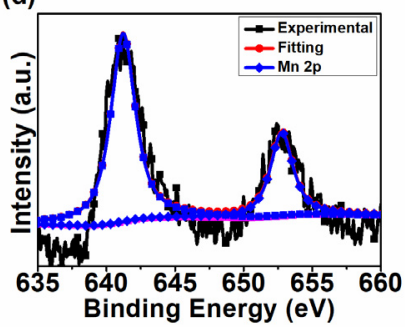

Fig. 5. XPS analysis of BFO-2. (a) Bi 4f; (b) Fe $2 p_{3 / 2}$ and $2 p_{1 / 2}$; (c) $01 s$; (f) Mn $2 p$.

for $\mathrm{Mn} 2 p_{3 / 2}$ and $2 p_{1 / 2}$ at 641.20 and $652.7 \mathrm{eV}$, respectively. Overall, $\mathrm{Mn}$ is evenly doped into the lattice of BFO in the $\mathrm{Mn}^{3+}$ oxidation state $[45,46]$, while $\mathrm{Fe}^{3+}$ is partially reduced to $\mathrm{Fe}^{2+}$.

\subsection{Photocatalytic activity and kinetics of photogenerated charge carriers}

Initially, four different sacrificial agents $\left(\mathrm{AgNO}_{3}\right.$, $\mathrm{Fe}\left(\mathrm{NO}_{3}\right)_{3} \cdot 9 \mathrm{H}_{2} \mathrm{O}, \mathrm{NaIO}_{3}$, and $\mathrm{Na}_{2} \mathrm{~S}_{2} \mathrm{O}_{8}$ ), were employed to identify the best reagent for the photocatalytic water oxidation reaction on BFO. Photocatalytic OER reactions were observed regardless of the sacrificial reagent. As shown in Fig. S3, when $\mathrm{Na}_{2} \mathrm{~S}_{2} \mathrm{O}_{8}$ was used as the sacrificial reagent, BFO exhibited the highest intrinsic photocatalytic OER activity of $70 \mu \mathrm{mol} \mathrm{h}^{-1} \mathrm{~g}^{-1}$. In addi- tion, we carried out photocatalytic OER reactions with and without BFO in dark conditions and without BFO under light irradiation, but no evolution of oxygen was observed. These control experiments confirm that BFO is a water oxidation photocatalyst. The photocatalytic OER activities of Mn-doped $\mathrm{BFO}\left(\mathrm{BFe}_{1-x} \mathrm{Mn}_{x} \mathrm{O}_{3}, x=0.025 \% 0.05 \%, 0.0750 \%\right.$, and $\left.0.1 \%\right)$ are shown in Fig. 6(a). Under the optimal (0.05\%) Mn doping conditions, the photocatalytic OER activity of BFO-2 reached 255 $\mu \mathrm{mol} \mathrm{h}{ }^{-1} \mathrm{~g}^{-1}$, which is the highest intrinsic photocatalytic OER activity for BFO-based materials (without any cocatalyst) reported so far (Table 1 in the SI). The time-dependent profiles of the photocatalytic OER reactions on BFO and BFO-2 are shown in Fig. 6(b). The amount of evolved oxygen steadily increased during the initial stage of $3 \mathrm{~h}$ and then reached a plateau, due to the consumption of the sacrificial reagents. The stability of BFO-2 against photocorrosion was assessed by retesting the OER activity of the recycled BFO-2 photocatalyst for three times, and the corresponding oxygen evolution rate is shown in Fig. S4. BFO-2 showed a high stability, as its photocatalytic OER rate remained constant over the three runs.

Photoluminescence (PL) spectra were recorded to further understand the role of Mn doping in the CST process. The photoluminescence emission (PLE) spectrum of BFO (Fig. 6(c)) shows five peaks at $c a .298,337,375,420$, and $555 \mathrm{~nm}$. According to previous reports, the peaks located at 298, 337, and $375 \mathrm{~nm}$ are due to intrinsic band-to-band transitions, while those at 420 and $555 \mathrm{~nm}$ are due to near-band-edge emission and defect trap states, respectively [47]. The PL spectra of pure BFO and BFO-2 were recorded at a $290 \mathrm{~nm}$ wavelength (Fig. $6(d)$ ). Both samples showed intrinsic fluorescence with maxima at $404 \mathrm{~nm}$, which could be as assigned to band-to-band transitions. The Mn-doped BFO-2 sample showed a much weaker fluorescence intensity compared to that of pure BFO, indicating a more efficient inhibition of the recombination of

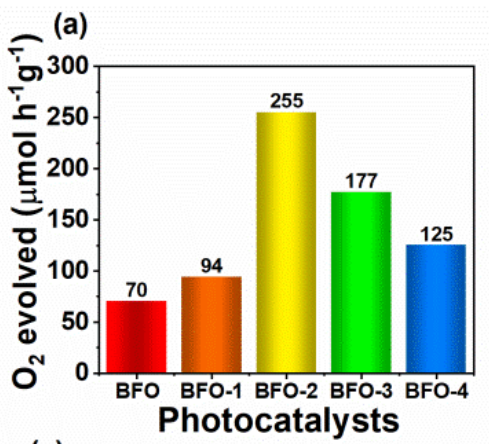

(b)

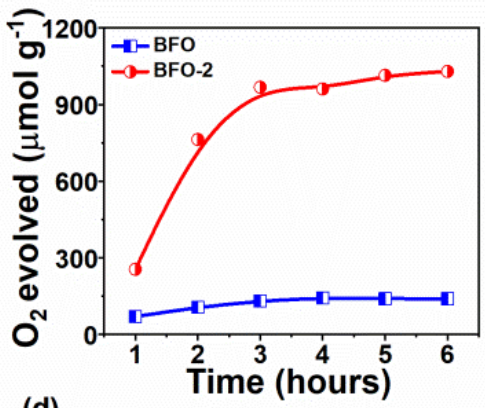

(c)

(d)
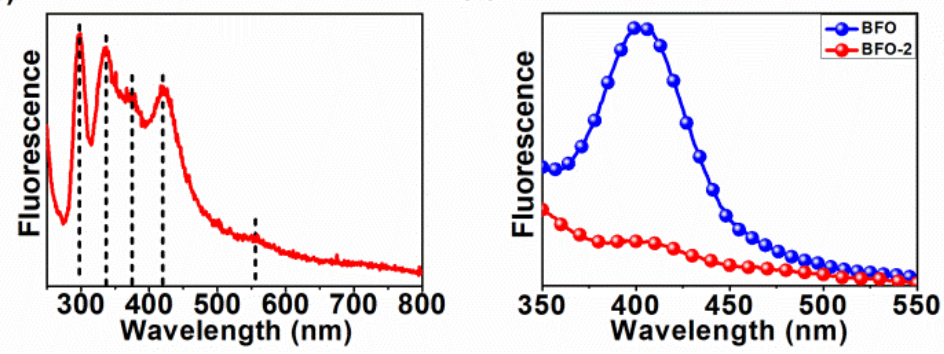

Fig. 6. (a) Photocatalytic water oxidation activity results of BFO, BFO-1, BFO-2, BFO-3 and BFO-4; (b) Time course of water oxidation activity test for BFO and BFO-2. (Reaction conditions: 0.1 g photocatalyst $+0.04 \mathrm{M} \mathrm{Na}_{2} \mathrm{~S}_{2} \mathrm{O}_{8}+150 \mathrm{~mL} \mathrm{H}_{2} \mathrm{O}$ under visible light irradiation $\geq 420 \mathrm{~nm}$ at $\mathrm{pH} 13.5$ ). $\mathrm{PL}$ studies of BFO and BFO-2: (c) PLE spectra for BFO using $290 \mathrm{~nm}$ excitation wavelength; (d) PL spectrum for BFO and BFO-2. 
(a)

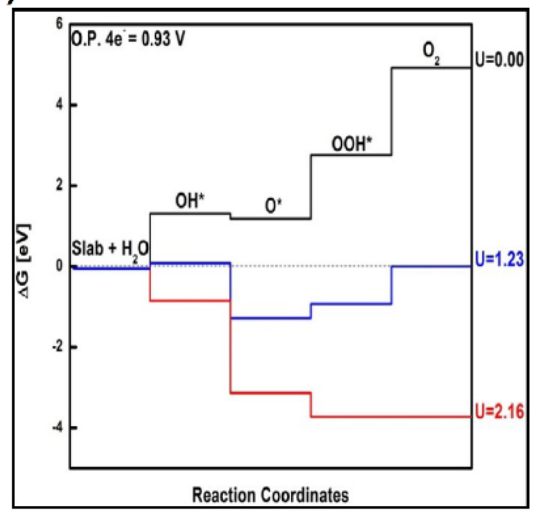

(b)

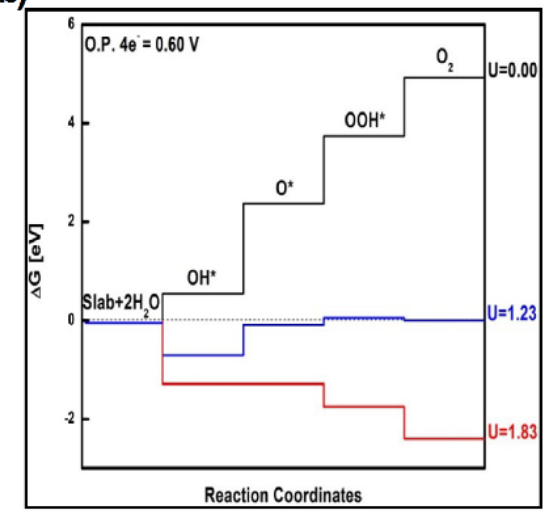

(c)

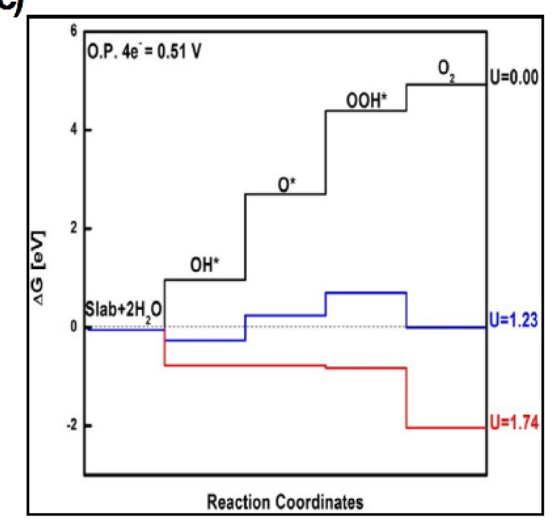

Fig. 7. (a) Free energy diagram for BFO; (b) BFO-2 with Mn as the metal active site; (c) BFO-2 with Fe as metal active site.

photogenerated charges via the fluorescence route $[48,49]$. The PL results confirm that Mn doping is beneficial for efficient separation and transfer of photogenerated charges.

\subsection{Intrinsic active sites for $O E R$}

To investigate the effect of Mn doping on the active sites for photocatalytic OER from a theoretical viewpoint, the surface orientation of the elements was first modulated by considering the different spin states (high and low spin) of Fe atoms in a layer-by-layer assembly. It turned out that the most stable structure of BFO involved anti-parallel layers with highly positive and negative spins on neutralized Fe atoms. The optimized structures of BFO and Mn-doped BFO-2 are shown in Figs. S5(a) and S5(b), while the structures involving intermediate active species for the OER are shown in Figs. S5(c-e).

Fig. 7 shows the free energies of the four OER reaction steps for the most stable (101) surfaces of BFO and BFO-2, based on the above model. The overpotential of the OER was calculated based on Eq. (9). For clean BFO, an overpotential of $0.93 \mathrm{~V}$ was obtained for the rate-determining step (Fig. 7(a)). For BFO-2, the overpotentials for $\mathrm{Fe}$ and $\mathrm{Mn}$ serving as active sites were $0.51 \mathrm{~V}$ (Fig. 7(b)) and $0.60 \mathrm{~V}$ (Fig. 7(c)), respectively, with a difference of $0.09 \mathrm{~V}$. Therefore, it can be concluded that $\mathrm{Mn}$ doping has a significant effect on the catalytic activity of BFO for the OER. This is in good agreement with the experimental findings, which showed that Mn-doped BFO-2 had much higher activity than BFO.

The photocatalytic OER process consists of three main steps: (1) light absorption, (2) photogenerated charge carrier (electron-hole) generation and transfer to the surface, and (3) redox reaction on the surface of the photocatalyst. All three steps must be considered during the design of photocatalysts for water splitting. The enhanced photocatalytic OER activity of Mn-doped BFO can be interpreted as originating from the synergetic improvement of these three key steps. As shown by the band structure analysis, Mn doping induces efficient visible light absorption, due to the bandgap narrowing. The more efficient separation of photogenerated charges was also confirmed by the PL measurements. Furthermore, the DFT calculations confirmed that Mn doping reduces the overpotential of Fe sites for the OER. The simultaneous improvement of light absorption, CST, and surface OER activity (in both thermodynamic and kinetic terms) is the origin of the enhancement of the photocatalytic OER activity of Mn-BFO.

\section{Conclusions}

In summary, this work shows that particulate BFO may exhibit intrinsic photocatalytic OER activity without deposition of any cocatalyst. Mn doping further enhances the photocatalytic water oxidation activity, leading to the best performance reported so far for BFO-based semiconductor photocatalysts. Experimental and theoretical studies were conducted to determine the intrinsic factors that enhance the photocatalytic water oxidation activity. It was found that Mn doping of BFO can significantly enhance the visible light absorption by reducing its bandgap energy from 2.1 to $1.36 \mathrm{eV}$. The PL spectra revealed that Mn doping can significantly reduce the recombination of photogenerated charges, that is, increase their separation efficiency. Interestingly, DFT calculations suggested that the active OER sites remained on the surface Fe species, but the overpotential was significantly reduced after Mn doping in BFO. The synergetic effect of the above properties enhanced the photocatalytic water oxidation activity of Mn-BFO. This work demonstrates that appropriate doping of ferroelectric BFO particulate photocatalysts is an effective strategy to improve the photocatalytic water oxidation activity. Additional studies of the relation between CST and ferroelectric properties as well as of the loading of different cocatalysts to further enhance the photocatalytic OER activity are still underway, and will be reported in an upcoming manuscript.

\section{Acknowledgments}

The authors thank the financial supports from National Natural Science Foundation of China (2176114208) and the Key Research and Development Program of the Ministry of Science and Technology of the People's Republic of China (2017YFA0204804). J. H. Shah and A. S. Malik contributed 


\section{Graphical Abstract}

\section{Chin. J. Catal., 2021, 42: 945-952 doi: 10.1016/S1872-2067(20)63713-5}

\section{Intrinsic photocatalytic water oxidation activity of Mn-doped ferroelectric $\mathrm{BiFeO}_{3}$}

Jafar Hussain Shah, Anum Shahid Malik, Ahmed Mahmoud Idris, Saadia Rasheed, Hongxian Han *, Can Li

Dalian Institute of Chemical Physics, Chinese Academy of Sciences;

University of Chinese Academy of Sciences

Mn-doped $\mathrm{BiFeO}_{3}$ enhances intrinsic photocatalytic OER activity due to synergetic improvement of light absorption and charge separation as well as lowering the water oxidation activation energy.

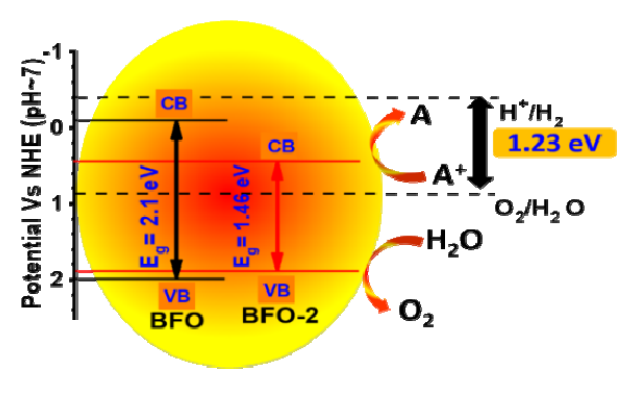

equally to this work as co-first authors.

\section{Electronic supporting information}

Supporting information is available in the online version of this article.

\section{Conflict of Interest}

The authors declare no conflict of interest.

\section{References}

[1] H. Tong, S. Ouyang, Y. Bi, N. Umezawa, M. Oshikiri, J. Ye, Adv. Mater., 2012, 24, 229-251.

[2] Y. Xu, A. Li, T. Yao, C. Ma, X. Zhang, J. H. Shah, H. Han, ChemSusChem, 2017, 10, 4277-4305.

[3] J. Huang, P. Yue, L. Wang, H. She, Q. Wang, Chin. J. Catal., 2019, 40, 1408-1420.

[4] J. Cui, T. Liu, Y. Qi, D. Zhao, M. Jia, G. Liu, F. Zhang, C. Li, J. Mater. Chem. A, 2017, 5, 18870-18877.

[5] Z. Wang, C. Li, K. Domen, Chem. Soc. Rev., 2019, 48, 2109-2125.

[6] S. Chen, Y. Qi, T. Hisatomi, Q. Ding, T. Asai, Z. Li, S.S.K. Ma, F. Zhang, K. Domen, C. Li, Angew. Chem., Int. Ed., 2015, 54, 8498-8501.

[7] K. Maeda, K. Teramura, D. Lu, T. Takata, N. Saito, Y. Inoue, K. Domen, Nature, 2006, 440, 295-295.

[8] I. Tsuji, H. Kato, A. Kudo, Angew. Chem., Int. Ed., 2005, 44, 3565-3568.

[9] G. Ma, S. Chen, Y. Kuang, S. Akiyama, T. Hisatomi, M. Nakabayashi, N. Shibata, M. Katayama, T. Minegishi, K. Domen, J. Phy. Chem. Lett., 2016, 7, 3892-3896.

[10] A. Ishikawa, T. Takata, T. Matsumura, J.N. Kondo, M. Hara, H. Kobayashi, K. Domen, J. Phy. Chem. B, 2004, 108, 2637-2642.

[11] Z.-K. Tang, C. Di Valentin, X. Zhao, L.-M. Liu, A. Selloni, ACS Catal,, 2019, 9, 10528-10535.

[12] V.-Q.-T. Hoang, T.-Q.-P. Phan, V. Senthilkumar, V.-T. Doan, Y.S. Kim, M.-V. Le, Int. J. Appl. Ceram. Technol., 2019, 16, 1651-1658.

[13] A. M. Idris, T. Liu, J. H. Shah, A. S. Malik, D. Zhao, H. Han, C. Li, ACS Appl. Mater. Interfaces, 2020, 12, 25938-25948.

[14] A. M. Idris, T. Liu, J. H. Shah, X. Zhang, C. Ma, A. S. Malik, A. Jin, S. Rasheed, Y. Sun, C. Li, H. Han, Solar RRL, 2020, 4, 1900456.

[15] A. M. Idris, T. Liu, J. Hussain Shah, H. Han, C. Li, ACS Sustainable
Chem. Eng., 2020, 8, 37, 14190-14197.

[16] S. Gao, B. Gu, X. Jiao, Y. Sun, X. Zu, F. Yang, W. Zhu, C. Wang, Z. Feng, B. Ye, J. Am. Chem. Soc., 2017, 139, 3438-3445.

[17] J. Li, G. Zhan, Y. Yu, L. Zhang, Nat. Commun., 2016, 7, 11480.

[18] H. Li, F. Qin, Z. Yang, X. Cui, J. Wang, L. Zhang, J. Am. Chem. Soc., 2017, 139, 3513-3521.

[19] H. Fujito, H. Kunioku, D. Kato, H. Suzuki, M. Higashi, H. Kageyama, R. Abe, J. Am. Chem. Soc., 2016, 138, 2082-2085.

[20] F. M. Toma, J. K. Cooper, V. Kunzelmann, M. T. McDowell, J. Yu, D. M. Larson, N. J. Borys, C. Abelyan, J. W. Beeman, K .M. Yu, Nat. Commun., 2016, 7, 12012.

[21] H. Shi, W. Ming, M.-H. Du, Phys. Rev. B, 2016, 93, 104108.

[22] A. Walsh, Y. Yan, M. N. Huda, M. M. Al-Jassim, S.-H. Wei, Chem. Mater., 2009, 21, 547-551.

[23] L. Chen, J. He, Y. Liu, P. Chen, C.-T. Au, S.-F. Yin, Chin. J. Catal., 2016, 37, 780-791.

[24] N. Rong, M. Chu, Y. Tang, C. Zhang, X. Cui, H. He, Y. Zhang, P. Xiao, J. Mater. Sci., 2016, 51, 5712-5723.

[25] Y. Ren, F. Nan, L. You, Y. Zhou, Y. Wang, J. Wang, X. Su, M. Shen, L. Fang, Small, 2017,13, 1603457.

[26] J. H. Shah, H. Ye, Y. Liu, A. M. Idris, A. S. Malik, Y. Zhang, H. Han, C. Li, J. Mater. Chem. A, 2020, 8, 6863-6873.

[27] S. Irfan, Y. Shen, S. Rizwan, H.-C. Wang, S. B. Khan, C.-W. Nan, J. Am. Ceram. Soc., 2017, 100, 31-40.

[28] K. Pang, Q. Zhang, Y. Xu, Ceram. Int., 2019, 45, 1554-1561.

[29] T. Tong, H. Zhang, J. Chen, D. Jin, J. Cheng, Catal. Commun., 2016, 87, 23-26.

[30] H. Tong, S. Ouyang, Y. Bi, N. Umezawa, M. Oshikiri, J. Ye, $A d v$. Mater., 2012, 24, 229-251.

[31] Z. Zhang, H. Liu, Y. Lin, Y. Wei, C.-W. Nan, X. Deng, J. Nanomater., 2012, 238605.

[32] P. R. Vanga, R. V. Mangalaraja, M. Ashok, J. Mater. Sci.: Mater. Electron., 2016, 27, 5699-5706.

[33] V. Singh, S. Sharma, M. Kumar, R. Dwivedi, AIP Conference Proceedings, 2014, 1591, 622-624.

[34] X. S. Xu, J. F. Ihlefeld, J. H. Lee, O. K. Ezekoye, E. Vlahos, R. Ramesh, V. Gopalan, X. Q. Pan, D. G. Schlom, J. L. Musfeldt, Appl. Phys. Lett., 2010, 96, 192901.

[35] Y. Feng, H. Wang, Y. Shen, Y. Lin, C. Nan, Mod. Res. Catal., 2013, 2, 1-5.

[36] S. Gupta, M. Tomar, V. Gupta, J. Appl. Phys., 2014, 115, 014102.

[37] B. Dhanalakshmi, K. Pratap, B. P. Rao, P. S. V. S. Rao, J. Alloys Compd., 2016, 676, 193-201

[38] M. Abushad, W. Khan, S. Naseem, S. Husain, M. Nadeem, A. Ansari, 
Ceram. Int., 2019, 45, 7437-7445.

[39] H. Matsuo, Y. Noguchi, M. Miyayama, Nat. Commun., 2017, 8, 207. [40] K. Singh, S.K. Singh, D. Kaur, Ceram. Int., 2016, 42, 13432-13441.

[41] P. Kubelka, Z. Tech. Phys., 1931,12, 593-601.

[42] J. H. Shah, M. Fiaz, M. Athar, J. Ali, M. Rubab, R. Mehmood, S. U. U. Jamil, R. Djellabi, Environ. Technol, 2020, 41, 2372-2381.

[43] G. S. Arya, N. S. Negi, J. Phys. D: Appl. Phys., 2013, 46, 095004.

[44] X. Ou, Y. Shuai, W. Luo, P.F. Siles, R. Kögler, J. Fiedler, H. Reuther, S. Zhou, R. Hübner, S. Facsko, M. Helm, T. Mikolajick, O. G. Schmidt, H.
Schmidt, ACS Appl. Mater. Interfaces, 2013, 5, 12764-12771.

[45] H. W. Nesbitt, D. Banerjee, Am. Mineral., 1998, 83, 305-315.

[46] M. Jiang, J. Chen, Y. Li, Chin. J. Catal., 2018, 39, 1017-1026.

[47] D. K. Pandey, A. Modi, P. Pandey, N. K. Gaur, J. Mater. Sci.: Mater. Electron., 2017, 28, 17245-17253.

[48] W. Zhao, Y. Wang, Y. Yang, J. Tang, Y. Yang, Appl. Catal. B, 2012, $115,90-99$.

[49] N. Zhang, D. Chen, F. Niu, S. Wang, L. Qin, Y. Huang, Sci. Rep., 2016, 6, 26467.

\title{
$\mathrm{Mn}$ 掺杂的铁电半导体 $\mathrm{BiFeO}_{3}$ 本征光催化氧化水活性的研究
}

\author{
Jafar Hussain Shah ${ }^{\mathrm{a}, \mathrm{b}}$, Anum Shahid Malik ${ }^{\mathrm{a}, \mathrm{b}}$, Ahmed Mahmoud Idris ${ }^{\mathrm{a}, \mathrm{b}}$, Saadia Rasheed ${ }^{\mathrm{a}, \mathrm{b}}$, \\ 韩洪宪 ${ }^{\mathrm{a}, *}$, 李 灿 ${ }^{\mathrm{a}}$ \\ ${ }^{\mathrm{a}}$ 中国科学院大连化学物理研究所, 洁净能源国家实验室(筹), 催化基础国家重点实验室太阳能部, 辽宁大连116023 \\ b中国科学院大学, 北京100049
}

\begin{abstract}
摘要: 开发稳定高效的可见光吸收的氧化物半导体光催化剂是太阳能光催化分解水的一个重要研究方向. 最近我们提出 (J. Mater. Chem. A, 2020, 8, 6863-6873), 具有室温铁电性质的 $\mathrm{BiFeO}_{3}(\mathrm{BFO})$ 薄膜体系表现出低光电流密度响应是由于铁电 畴壁/界面处的电荷复合, 而该作用在纳米粒子催化剂体系中应该会大大减少. 为了证明这一观点, 我们通过溶胶-凝胶法 合成了 $\mathrm{BFO}$ 纳米粒子, 并进行了 $\mathrm{Mn}$ 掺杂获得了 $\mathrm{Mn}-\mathrm{BFO}$. 光催化水氧化反应表明, 纯 BFO具有光催化氧化水的活性, 析氧数 率达到 $70 \mu \mathrm{mol} \mathrm{h}^{-1} \mathrm{~g}^{-1}$; 而 $\mathrm{Mn}$ 掺杂量优化 $(0.05 \%)$ 后的 Mn-BFO在可见光 $(\lambda \geq 420 \mathrm{~nm})$ 照射下的析氧活性大大提高, 达到 255 $\mu \mathrm{mol} \mathrm{h} \mathrm{h}^{-1} \mathrm{~g}^{-1}$. 带隙研究表明, 通过改变Mn的掺杂量, 可以将Mn-BFO的带隙从 $2.1 \mathrm{eV}$ 调整为 $1.36 \mathrm{eV}$. DFT计算表明, 表面的 $\mathrm{Fe}$ 物种是水氧化的活性位点, 而不是 $\mathrm{Mn}$ 物种, 因为 $\mathrm{Mn}$ 掺杂后 $\mathrm{Fe}$ 物种的水氧化过电势 $0.51 \mathrm{~V}$, 是所考察的表面 $\mathrm{Fe}$ 和 $\mathrm{Mn}$ 物种 中过电势中最低的. 因此, Mn-BFO光催化水氧化活性的增强可归因于半导体带隙变窄后吸收更多的可见光、降低了的水 氧化过电势以及抑制光生电荷复合这几项的协同效应. 这项工作表明, 锰掺杂是提高纳米粒子铁电BFO光催化剂固有光催 化水氧化活性的有效策略.
\end{abstract}

本文采用溶胶-凝胶法成功制备了锰掺杂的BFO样品, 并使用XRD, DRS, Mott-Schottky, XPS和PL等进行了表征. XRD 分析结果表明, Mn掺杂后, BFO的(110)和(104)衍射峰向高位衍射角方向位移合并产生一个更宽的峰, 表明Mn的掺杂引起 BFO晶格结构变形. DRS光谱分析表明, Mn的掺杂可以拓展可见光的吸收, 从纯BFO的 $550 \mathrm{~nm}$ 吸收边 (对应于 $2.1 \mathrm{eV}$ 的带 隙)扩展到BFO-2 的 $800 \mathrm{~nm}$ (对应于 $1.46 \mathrm{eV}$ 的带隙)吸收带边. 这些结果与用DFT计算DOS分析得到的BFO和BFO-2理论带 隙值 2.05 和 $1.53 \mathrm{eV}$ 一致. Mott-Schottky分析表明, BFO和BFO-2 是 $\mathrm{p}$ 型半导体, 其平带 $(\mathrm{Vfb})$ 电势分别为 1.7 和 $1.6 \mathrm{~V} v s \mathrm{NHE}$, $\mathrm{VB}$ 位置估计分别为 2.0 和 $1.9 \mathrm{~V} v s \mathrm{NHE}$, 而 CB位置估计分别为 -0.11 和 $0.44 \mathrm{~V} v s$ NHE. 因此, Mn-BFO在热力学有利于光催 化OER但不利于HER. 从 Mn-BFO的XPS光谱可以看出除了 $\mathrm{Bi}, \mathrm{Fe}$ 和O光谱外, 也可以在 641.20 和 $652.7 \mathrm{eV}$ 处观察到出 $\mathrm{Mn}$ $2 p_{3 / 2}$ 和 $2 p_{1 / 2}$, 表明 $\mathrm{Mn}$ 是以 $\mathrm{Mn}^{3+}$ 的形式均匀地掺入 $\mathrm{BFO}$ 的晶格中. 对一系列不同含量 $\mathrm{Mn}$ 掺杂的 Mn-BFO的光催化OER活性 表明研究表明, $0.05 \% \mathrm{Mn}$ 掺杂的BFO-2的光催化OER活性最优, 其析氧活性达到 $255 \mu \mathrm{mol} \mathrm{h}^{-1} \mathrm{~g}^{-1}$, 这是迄今为止未加载任何 助催化剂的BFO的最高固有光催化OER活性值. PL光谱(290 nm激发)显示, 与纯BFO相比, BFO-2的荧光强度弱得多, 表明 $\mathrm{Mn}$ 的掺杂可以抑制光生电荷的复合. DFT计算显示, BFO的表面Fe活性中心的OER过电势为 $0.93 \mathrm{~V}$; 而对于 $\mathrm{Mn}$ 掺杂的 BFO-2, 理论计算得到表面 $\mathrm{Fe}$ 中心和 $\mathrm{Mn}$ 中心的析氧过电位分别为 0.51 和 $0.60 \mathrm{~V}$. 由此可见, $\mathrm{Mn}$ 掺杂不改变BFO的析氧活性 中心, 但是可大大降低Fe活性中心OER过电位, 这与锰掺杂的BFO-2 表现出比BFO更高光催化氧化水的催化活性实验结果 相一致.

综上所述, 在纳米粒子光催化体系中, $\mathrm{Mn}$ 掺杂的BFO可以促进可见光的吸收, 促进光生电荷有效分离, 降低表面 $\mathrm{Fe}$ 基 活性中心氧化水的过电位, 从而显著提高光催化氧化水的活性. Mn的掺杂对于铁电性质的影响及其光催化活性的关系, 有 待进一步探索.

关键词: 光催化水氧化; 带隙工程; 铁酸铋; 铁电材料; 阳离子掺杂

收稿日期: 2020-07-21. 接受日期: 2020-09-21. 上网日期: 2020-11-22.

*通讯联系人. 电话: (0411)84379760; 传真: (0411)84694447; 电子信箱: hxhan@dicp.ac.cn 基金来源：国家自然科学基金中韩国际合作项目(2176114208); 科技部重点研发计划项目课题(2017YFA0204804).

本文的电子版全文由Elsevier出版社在ScienceDirect上出版(http://www.sciencedirect.com/science/journal/18722067). 